\title{
Analysis of Classification Systems and Outcome of Labor in Women Undergoing Induction of Labor in South Indian Population
}

\author{
Seetha Panicker ${ }^{1}$, Sumangali Thirunavukkarasu' ${ }^{2}$, Chitra Bhat ${ }^{3}$
}

\begin{abstract}
Aim and objective: To identify women undergoing induction of labor ( $\mathrm{IOL})$ for 1 year in our tertiary care hospital, apply the classification systems, correlate with the maternal and fetal outcomes, and determine the ease and effectiveness of audit of the IOL practice.

Materials and methods: All patients who delivered in the year 2019 were analyzed, and the cohort of women who underwent IOL was identified. The age, parity, gestational age at induction, indication for induction, and the maternal and fetal outcomes were analyzed. The two classification systems were applied and the results were analyzed.

Results: The total number of deliveries for the year was 3,668, and the number of women undergoing IOL was 1,450, with an incidence of 39.5\%. The maximum number of women, 1,212, (83.5\%) were in the 20-30-year age-group; in that, 1107 (76.34\%) were primiparous and 343 (23.66\%) were multiparous. The commonest indication for IOL was postdates, with the commonest mode being PGE2 gel in 699 (48.2\%) women. Of 1,450 women induced, 1,083 (74.69\%) had a vaginal delivery and $367(25.31 \%)$ delivered by a cesarean section. This was similar to the rate seen in women with spontaneous labor. Further, a 10-group classification system according to Nippita et al. and classification of IOL according to the indication for induction proposed by Mahomed et al. was applied to this cohort.

Conclusion: The classification systems are useful to determine whether the induction is done according to the established guidelines and makes our audit easier. A prospective audit would better identify some of the adverse maternal and fetal outcomes.

Clinical implications: The safety of IOL in modern obstetrics should not give us a false sense of security, and regular audits of the practice of $\mathrm{IOL}$ are useful to ensure that the adherence is according to the established guidelines.

Keywords: Cesarean section, Labor induction, Neonatal outcome, Obstetric complications, Obstetric outcome, Preinduction cervical ripening. Journal of South Asian Federation of Obstetrics and Gynaecology (2021): 10.5005/jp-journals-10006-1940
\end{abstract}

\section{INTRODUCTION}

Induction of labor (IOL) is one of the most commonly performed interventions in obstetrics. It is indicated that the risks of continuing the pregnancy outweigh the risks associated with the induction process.

Globally labor is induced in about $20-30 \%$ of all deliveries for a variety of reasons. ${ }^{1}$ Although induction is generally considered a safe process, there are still some concerns like increased rate of tachysystole and the requirement for increased monitoring in labor and epidural analgesia. In addition, there are concerns that delivery by cesarean section for failed induction, failure to progress, or fetal distress and postpartum hemorrhage (PPH) may also be increased. These risks may be inherent to the induction process and may be justified provided that the maternal or fetal risks of continuing the pregnancy outweigh these risks.

Analysis of induction rates is part of the monthly audit of performance indicators carried out in the Department of Obstetrics and Gynaecology in a teaching hospital in South India with a moderately busy obstetric unit of 3,500-3,700 deliveries per year.

However, the audit was proved to be difficult as the monthly rates were variable and monitoring the rates and outcome did not contribute significantly to the measures to improve the quality of care.

A classification system for women undergoing IOL has been proposed by Nippita et al. ${ }^{2}$ based on parity, the number of fetuses, and gestational age. Mahomed et al. ${ }^{3}$ proposed a classification
${ }^{1-3}$ Department of Obstetrics and Gynaecology, PSG Institute of Medical Sciences and Research, Coimbatore, Tamil Nadu, India

Corresponding Author: Sumangali Thirunavukarasu, Department of Obstetrics and Gynaecology, PSG Institute of Medical Sciences and Research, Coimbatore, Tamil Nadu, India, Phone: +91 9488045005, e-mail: drsumangali@hotmail.com

How to cite this article: Panicker S, Thirunavukkarasu S, Bhat C. Analysis of Classification Systems and Outcome of Labor in Women Undergoing Induction of Labor in South Indian Population. J South Asian Feder Obst Gynae 2021;13(5):310-314.

Source of support: Nil

Conflict of interest: None

system, incorporating the primary indication for induction in addition to the gestational age.

This retrospective study was undertaken to analyze women undergoing IOL for 1 year period from January 2019 to December 2019. Both classification systems were applied, and the outcome of labor was analyzed.

\section{Aim and Objective}

To identify women undergoing IOL for 1 year, apply the two classification systems, correlate with maternal and fetal outcomes, and determine the ease and effectiveness of audit of the $\mathrm{OOL}$ practice.

() The Author(s). 2021 Open Access This article is distributed under the terms of the Creative Commons Attribution 4.0 International License (https://creativecommons. org/licenses/by-nc/4.0/), which permits unrestricted use, distribution, and non-commercial reproduction in any medium, provided you give appropriate credit to the original author(s) and the source, provide a link to the Creative Commons license, and indicate if changes were made. The Creative Commons Public Domain Dedication waiver (http://creativecommons.org/publicdomain/zero/1.0/) applies to the data made available in this article, unless otherwise stated. 


\section{Materials and Methods}

Approval from the institutional human ethics committee was obtained (IHEC Project No 18/277) for a retrospective observational study.

This study was done at a teaching hospital in South India with a moderately busy obstetric unit, with 3,500-3,800 deliveries per year. We are involved in teaching undergraduate and postgraduate as well as nursing students. The hospital also acts as a referral center for highrisk patients from the surrounding clinics. All patients who delivered between January 1, 2019, and December 31, 2019, were analyzed, and the cohort of women who underwent IOL was identified. The age, parity, gestational age at induction, indication for induction, and the maternal and fetal outcomes were analyzed. The two classification systems were applied, and the results were analyzed to determine if the audit is easier and more effective.

\section{Results}

The total number of deliveries for 1 year from January 1, 2019, to December 31, 2019, was 3,668.

The number of women undergoing $\mathrm{IOL}$ during this period was 1,450 , with an incidence of $39.5 \%$.

The age distribution of patients undergoing $\mathrm{IOL}$ was analyzed, and it was found that the largest number of women 1,212 (83.5\%) was in the 20-30-year age-group. Twenty-three (1.5\%) women were above 35 years and 68 (4.6\%) were less than 20 years of age.

Of the 1,450 induced patients, $1,107(76.34 \%)$ were primigravida and 343 (23.66\%) were multigravida.

Table 1 shows the indication for $\mathrm{IOL}$, and it was found that the commonest indication was postdates and premature rupture of membranes followed by fetal growth restriction (FGR) and diabetes complicating pregnancy.

The primary mode of induction in this cohort was based on the Bishop score at the time of induction ${ }^{4}$ and the commonest mode was PGE2 gel in 699 (48.2\%) women followed by oral misoprostol in 566 (39\%), and 74 (5.1\%) were induced by mechanical methods.

Table 1: Indications for IOL

\begin{tabular}{lcc}
\hline Indications for IOL & No of patients & Percentage \\
\hline $\begin{array}{l}\text { Postdates/estimated date of } \\
\text { delivery (EDD) }\end{array}$ & 413 & 28.48 \\
PROM & 338 & 23.31 \\
FGR & 181 & 12.4 \\
Gestational diabetes mellitus & 181 & 12.4 \\
(GDM)/overt DM & & \\
Preeclampsia/chronic & 82 & 5.65 \\
hypertension (HT) & & \\
Social & 114 & 7.86 \\
Oligohydramnios & 66 & 4.5 \\
Polyhydramnios & 13 & 0.89 \\
Intrauterine fetal demise (IUFD) & 17 & 1.17 \\
BOH & 17 & 1.17 \\
Fetal anomaly & 6 & 0.41 \\
Rh isoimmunization & 8 & 0.55 \\
Elderly primi & 2 & 0.13 \\
Others (hypertrophic obstructive & 12 & 0.82 \\
cardiomyopathy (HOCM), bipolar & & \\
disorder, antepartum haemorrhage & & \\
(APH) in vitro fertilization (IVF), sickle & & \\
cell disease) & & \\
\hline
\end{tabular}

The number of patients who received epidural analgesia in this group was 189 (13\%). Patients in spontaneous labor during the study period were 1,671; of which 135 (8\%) required epidural analgesia. This difference was statistically significant ( $p$ value 0.001 ). The mode of delivery in women who were induced was analyzed, and of 1,450 women, 1,083 (74.69\%) had a vaginal delivery and $367(25.31 \%)$ delivered by a cesarean section. Women who had spontaneous labor during the same period were analyzed and the rate of cesarean section was found to be $25.37 \%$ which was similar to those who had induced labor.

Flowchart 1 shows the 10-group classification system according to Nippita et al. ${ }^{2}$ and Flowchart 2 shows that this cohort was divided into groups according to this classification system.

Tables 2 and 3 show primigravida and multigravida classification according to the indication for induction and gestational age.

Table 4 shows the outcome of babies at birth which was analyzed according to the Apgar scores at birth and at 5 minutes and the rate of NICU admissions. The number of babies with an Apgar equal or less than 6 was 72 (4.9\%), and the number of NICU admissions in patients undergoing $\mathrm{IOL}$ at different gestational ages was 96 (6.62\%). The most common reason for an NICU admission was for preterm care in 59 (4.06\%) neonates and 11 (0.75\%) were admitted for meconium-stained amniotic fluid.

\section{Discussion}

Induction of labor (IOL) is one of the most commonly performed interventions in obstetrics. The increasing effectiveness and safety of induction have resulted in increased rates of induction for many reasons including social reasons for the convenience of the patient and the obstetrician or to ensure that the majority of deliveries are in the daytime when staffing is at its maximum.

The percentage of patients undergoing $\mathrm{IOL}$ is one of the key performance indicators of an obstetric unit. ${ }^{5}$ Hence, an audit of this practice is important for two reasons. The first is to ensure that the intervention is according to the established guidelines. ${ }^{6}$ The second is to determine if there are adverse maternal or fetal outcomes associated with the intervention. IOL also has a significant impact on women's experience of labor and delivery. ${ }^{7}$ However, the audit of women undergoing IOL is not easy as it includes not only the rate of induction but also the indication for induction, the gestational age at which the indication was undertaken, and the maternal and fetal outcomes. Hence, the classification of women undergoing $\mathrm{IOL}$ would be helpful in the audit as well as useful in following the practice of induction over time.

Analyzing our results, we found that our induction rate during this period was $39.5 \%$. Comparing this with reported rates of induction, we found that the NHS Maternity Statistics UK 2013-2014 reported that the rates of induction have increased over a 10-year period from $15.4 \%$ in $2003-2004$ to $21.2 \%$ in $2013-2014 .{ }^{8}$ The rates of IOL for a singleton pregnancy were reported as $23.8 \%$ in the United States in $2010 .{ }^{9}$ The rate of induction in Canada has steadily increased from $12.9 \%$ in 1992 to $21.8 \%$ in 2004 and has since remained steady. ${ }^{4}$ Unpublished data from the WHO Global Survey on Maternal and Perinatal Health which included 373 healthcare facilities in 24 countries and nearly 300,000 deliveries showed that $9.6 \%$ of deliveries involved labor induction. Overall, the survey found that facilities in African countries tended to have lower rates of IOL (lowest Niger 1.4\%) compared with Asian and Latin-American countries (highest Sri Lanka 35.5\%). ${ }^{1}$ 
Flowchart 1: Hierarchical nature of the 10-group classification system of IOL proposed by Nippita et al.

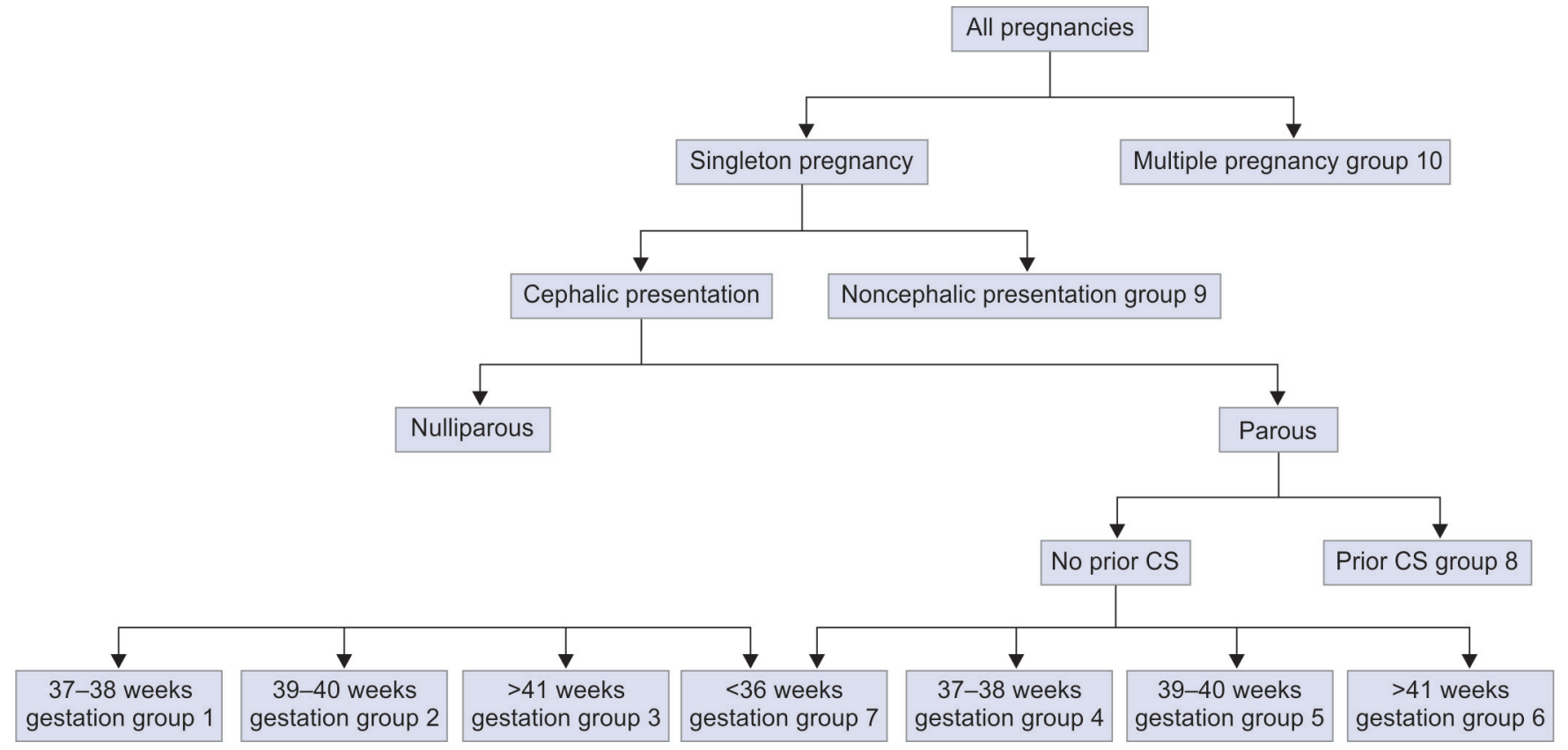

Flowchart 2: Classification of study group according to Nippita et al.

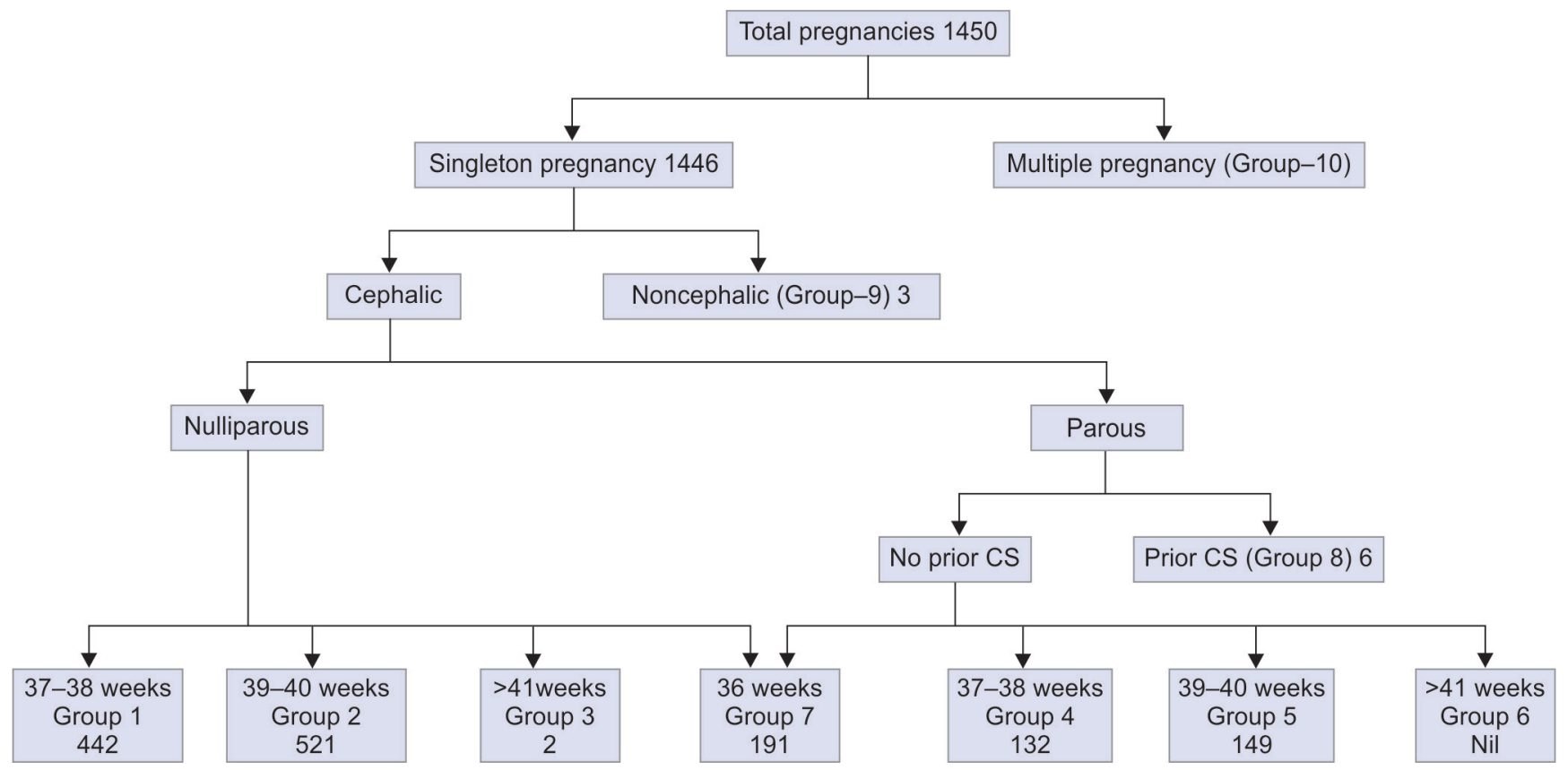

On analyzing the indication for induction, it was found that postdates (28.48\%) and premature rupture of membranes (23.31\%) were the commonest indications followed by FGR (12.4\%) and diabetes in pregnancy (12.4\%). In addition, in 114 patients (7.8\%), the indication was social. This was a significant number and included patients who requested delivery on an auspicious day or complained of decreased fetal movements or false pains and were anxious about the outcome. ${ }^{10}$ It is important to ensure that, in this group, IOL is done only after 39 weeks. ${ }^{11}$ According to Mast et al., the indications for induction included fetal indications, like
FGR, macrosomia, diabetes, postterm pregnancy, and (premature rupture of membranes) PROM. The maternal indications included hypertension, previous $\mathrm{CS}$, and maternal request. ${ }^{12}$

Nippita et al. in 2015 published a systematic review including seven studies that categorized women according to the presence or absence of varying medical indications for IOL. A classification system of 10 groups was developed based on parity, gestational age, and the number and presentation of the fetus. ${ }^{2,13}$ Flowchart 2 shows the cohort classified according to this classification system. It was found that the largest number of 521 
Table 2: Primiparous women. Indication for IOL according to gestational age

\begin{tabular}{|c|c|c|c|c|c|c|}
\hline Indication for IOL & $24-28$ & $28+1-36+6$ & $37-38+6$ & $39-40$ & $>40$ weeks & $>41$ weeks \\
\hline Postdates/EDD & - & - & - & 125 & 191 & 2 \\
\hline $\mathrm{PE} / \mathrm{CH} \mathrm{HT}$ & 1 & 29 & 29 & 7 & - & - \\
\hline DM/GDM & - & 2 & 98 & 28 & 4 & - \\
\hline FGR/SGA & - & 30 & 97 & 12 & - & - \\
\hline BOH/APLA & - & 1 & 8 & - & - & - \\
\hline IUFD & - & 4 & 3 & 3 & - & - \\
\hline PROM & 1 & 58 & 136 & 71 & 2 & - \\
\hline Rh neg/ISO & - & - & 3 & - & - & - \\
\hline Oligo & - & 11 & 22 & 19 & - & - \\
\hline Fetal anomaly & - & 1 & 3 & 1 & - & - \\
\hline Social & - & - & 35 & 50 & - & - \\
\hline Poly & - & - & 4 & 7 & - & - \\
\hline Elderly gravida & - & - & 2 & - & - & - \\
\hline Others & - & 3 & 2 & 2 & - & - \\
\hline
\end{tabular}

Table 3: Multiparous women. Indication for IOL according to gestational age

\begin{tabular}{|c|c|c|c|c|c|c|}
\hline Indication for IOL & $24-28$ & $28+1-36+6$ & $37-38+6$ & $39-40$ & $>40$ weeks & $41+$ \\
\hline Postdates/EDD & - & - & - & 39 & 56 & - \\
\hline $\mathrm{PE} / \mathrm{CH} \mathrm{HT}$ & - & 9 & 7 & - & - & - \\
\hline DM/GDM & - & 3 & 34 & 11 & 1 & - \\
\hline $\mathrm{FGR} / \mathrm{SGA}$ & - & 12 & 26 & 4 & - & - \\
\hline $\mathrm{BOH}$ & - & 2 & 6 & - & - & - \\
\hline IUFD & - & 6 & - & 1 & - & - \\
\hline PROM & 3 & 18 & 29 & 18 & 2 & - \\
\hline Rh/isoimmunized & - & 1 & 4 & - & - & - \\
\hline Oligo & - & 2 & 8 & 4 & - & - \\
\hline Fetal anomaly & - & - & 1 & - & - & - \\
\hline Social & - & - & 15 & 14 & - & - \\
\hline Poly & - & 1 & - & 1 & - & - \\
\hline Others & - & - & 4 & 1 & - & - \\
\hline
\end{tabular}

Table 4: Neonatal outcomes

\begin{tabular}{lcc}
\hline Gestational age in weeks & Apgar scores $<$ or $=6$ & No of NICU admissions \\
\hline$<28$ weeks & 3 & 3 \\
$28-37$ weeks & 24 & 56 \\
$37-40$ weeks & 31 & 26 \\
$>40$ weeks & 14 & 11 \\
\hline
\end{tabular}

(35.93\%) was in group 2 which was nulliparous women between 39 and 40 weeks. This is similar to the results by Nippita et al., where they found that nulliparous and parous women at full term were the largest groups 21.2 and $24.5 \%$, respectively. Group 1 that includes nulliparous women between 37 and 38 weeks had 442 (30.5\%) patients. However, it was difficult to audit this group without including the indication for induction. Many of our patients were induced at $40+$ weeks under the premise that southeast Asian babies tend to mature earlier. These women who were induced at $40+1$ to $40+6$ weeks were included in groups 2 and 5, respectively. Group 8 (previous CS), group 9 (noncephalic), and group 10 (multiple pregnancies) had only 6, 3, and 4 patients, respectively. The noncephalic group was mainly induced for intrauterine fetal death.
On auditing this cohort, we were able to determine that the largest numbers were in groups 2 and 5 of about 670 (46\%). This included both primi- and multigravida at 39-40 + 6 weeks. Patients $>41$ weeks were placed in groups 3 and 6 which had very small numbers.

Tables 2 and 3 show primigravida and multigravida classification according to the indication for induction and the gestational age at which it was carried out as proposed by Mahomed et al. ${ }^{3}$ They found that the commonest indication for IOL was postdates which accounted for $27.6 \%$. The advantage of including the indication for IOL is two-fold. For most of the indications included in their list, there are evidence-based guidelines, and we can determine if we are adhering to these guidelines. ${ }^{4,14}$ Secondly, we can concentrate on areas for improvement targeted at a specific group rather than the entire population. On analyzing our cohort, we found that the largest group of patients (674) was induced between 39 and 41 weeks. In patients who were induced before 37 weeks, the indication for induction like preeclampsia or PROM helped to determine whether the induction was appropriate.

Although $I O L$ is a safe procedure, an audit of the process would be incomplete without including the maternal and fetal outcomes. ${ }^{15}$ On analyzing the mode of delivery, we found that 1,083 women (74.69\%) 
had a vaginal delivery. The incidence of a cesarean section was $25.31 \%$ which is similar to the rate in the spontaneous labor group (25.37\%); however, a meta-analysis of various RCTs was done by Mishanina et al. and showed that the risk of cesarean section was lower among the women whose labor was induced than those managed expectantly. ${ }^{16}$ The need for epidural analgesia in our cohort was higher in those induced compared to those in spontaneous labor which was similar to the data published by Poma et al. ${ }^{17}$ but the duration of labor could not be compared in our study as it is a retrospective study.

On analyzing the fetal outcome, we found that babies with an Apgar score equal to or less than 6 were 72 (4.9\%) and the number of NICU admissions was 96 (6.62\%) which was comparable to women with spontaneous onset of labor. ${ }^{18}$

\section{Conclusion}

A regular audit of labor ward practice to measure compliance against standards is important to ensure the quality of care. However, an audit of $\mathrm{IOL}$ is not easy as many factors have to be taken into account. Classifying the cohort of women undergoing IOL into groups would make the process easier and more standardized. The 10-group classification is based on parity and gestational age and helps divide the cohort into specific groups. The addition of the indication for IOL would add value to ensure that IOL is done according to the established guidelines. So, the classification systems are useful to determine whether the IOL is done according to the established guidelines. However, the second part of the audit to determine whether there are adverse maternal or fetal outcomes associated with the intervention would include factors like the duration of labor, mode of delivery, maternal complications like tachysystole or PPH and fetal complications like decelerations in labor or meconiumstained amniotic fluid. Some of these factors are best identified in a prospective audit and would what is ideal if circumstances permit. The safety of IOL in modern obstetrics should not give us a false sense of security and we should take all measures to ensure that our practice is according to the highest standards.

\section{References}

1. World Health Organisation. WHO recommendations for induction of labour. Geneva: WHO; 2010.

2. Nippita TA, Khambalia AZ, Seeho SK, et al. Methods of classification for women undergoing induction of labour: a systematic review and novel classification system. BJOG 2015;122(10):1284-1293. DOI: 10.1111/1471-0528.13478.

3. Mahomed K, Ying HE, Holland L. Induction of labour classification can we explain variation in induction rates? Obstet Gynecol Int J 2018;9(3):164-166. DOI: 10.15406/ogij.2018.09.00324.
4. Leduc $D$, Biringer $A$, Lee $L$, et al. Induction of labour. J Obstet Gynaecol Can 2013;35(9):840-857. DOI: 10.1016/S1701-2163(15)30842-2.

5. Esposito P, Dal Canton A. Clinical audit, a valuable tool to improve quality of care: general methodology and applications in nephrology. World J Nephrol 2014;3(4):249-255. DOI: 10.5527/wjn. v3.i4.249.

6. Mousa HA, Mahmood TA. Do clinical practice guidelines guide practice? A prospective audit of induction of labour - three years experience. Acta Obstet Gynecol Scand 2000;79(12):1086-1092. PMID: 1130093.

7. O'Dwyer S, Raniolo C, Roper J, et al. Improving induction of labour a quality improvement project addressing Caesarean section rates and length of process in women undergoing induction of labour. BMJ Qual Improv Rep 2015;4(1):u203804.w4027 DOI: 10.1136/bmj quality.u203804.w4027.

8. Health and Social Care Information Centre. NHS Maternity Statistics, England, 2013-14. Available from: https://digitals.nhs.uk/catalogue/ PUB16725.

9. Osterman M, Martin J. Recent declines in induction of labour by gestational age. NCHS Data Grief 2014;(155): 1-8. PMID: 24941926.

10. Ananth CV, WilcoxAJ, Gyamfi-Bannerman C. Obstetrical interventions for term first deliveries in the US. Paediatr Perinat Epidemiol 2013;27(5):442-451. DOI: 10.1111/ppe.12068.

11. Grobman WA, Rice MM, Reddy UM, et al. Labour induction versus expectant management in low risk nulliparous women. N Engl J Med 2018;379(6):513-523. DOI: 10.1056/NEJMoa1800566.

12. Mast K, Mieke LG, Bloemenkampis KWM, et al. Chapter 13. Induction of labour: who, when, how and where? In: Ledger W, Clark J, editors. Recent advances in obstetrics and gynaecology: 26. New Delhi: JP Publishers; 2015. p. 135-147.

13. Betrán AP, Vindevoghel N, Souza JP, et al. A systematic review of the Robson classification for caesarean section: what works, doesn't work and how to improve it. PLoS One 2014;9(6):e97769. DOI: 10.1371/ journal.pone.0097769.

14. ACOG Committee on Practice Bulletins: Obstetrics. ACOG Practice Bulletin no 107: induction of labor. Obstet Gynecol 2009;114(2 Pt 1):386-397. DOI: 10.1097/AOG.0b013e3181b48ef5.

15. Norman JE, Stock SJ. Chapter 24 Induction and augmentation of labour. In: Edmonds DK, Lees C, Bourne T, editors. Dewhurst's textbook of obstetrics and gynecology. Wiley Blackwell Publishing Ltd; 2018. p. 326-335.

16. Mishanina $E$, Rogozinska $E$, Thatthi $T$, et al. Use of labour induction and risk of cesearean delivery: a systematic review and meta-analysis. CMAJ 2014;186(9):665-673. DOI: 10.1503/cmaj.130925.

17. Poma S, Scudeller L, Gardella B, et al. Outcomes of induced versus spontaneous labor. J Matern Fetal Neonatal Med 2017;30(10):11331138. DOI: 10.1080/14767058.2016.1205028.

18. Gulmezoglu AM, Crowther CA, Middleton P, et al. Induction of labour for improving birth outcomes for women at or beyond term. Cochrane Database Syst Rev 2012;6(6):CD004945. DOI: 1002/14651858.CD004945.pub3. 